\title{
The hackathon format: an analysis of its possible interpretations under a service design perspective
}

\author{
Amalia de Götzen1, Luca Simeone2, Nicola Morelli3 , Joanna Saad Sulonen4 Begüm \\ Becermens \\ IAalborg University \\ ago@create.aau.dk \\ 2Aalborg University \\ lsi@create.aau.dk \\ 3Aalborg University \\ nmor@create.aau.dk3 \\ 4IT-University of Copenhagen \\ jsaa@itu.dk \\ 5Aalborg University \\ beg@create.aau.dk
}

\begin{abstract}
In the last decade, many different participatory spaces emerged in the cities' ecosystems, from makers/hackers spaces to hack-labs, actively contributing to the creation of Public Innovation Spaces (Manzini \& Staszowski, 2013) and increasingly adopting design enabled innovation in different forms to produce new solutions to emerging problems (Concilio et al., 2018). Among the different participatory activities in such places, hackathons have emerged as a format to gather participants and jointly work on issues of common interest or to propose the design of new services. The format of the hackathon has changed over time, from spontaneous and selforganized gatherings, all the way up to structured and professionally organized corporate sponsored events. This paper intends to explore this phenomenon by a retrospective reflection over the experience of the authors as participants or organizers of 5 hackathons that took place between 2011 and 2017. The paper will analyse the way in which these hackathons were prepared and run and how their different formats affected both the selection of participants and the outcomes of the hackathons. Related issues such as self-organization vs. top-driven governance will also be investigated to propose some considerations on the creative serendipity one would expect from such events.
\end{abstract}

Keywords: Hackathons, participation, innovation, service design 


\section{Introduction}

In the past few years, hackathons have emerged as a format to gather participants and jointly work on issues of common interest. While at the end of the 1990s hackathons were niche events mostly organized and attended by open-source software developers (Briscoe \& Mulligan, 2014), nowadays the format of the hackathon - appropriated or reinvented by design, innovation and start-up communities - is increasingly used to organize events attended by a variety of participants (including non-expert programmers) and aimed at different scopes, from exploring new production processes (Tanenbaum et al., 2014), to tackling social issues through humanitarian technology (Linnell, Figueira, Chintala, Falzarano, \& Ciancio, 2014), all the way up to prototyping a new generation of services and new ways of commoning (Morelli et al., 2017). At the same time, in the last decade, the ecosystems of citizen participation and innovation have significantly changed with the proliferation of participatory spaces where citizens can "make" their own products or "hack" their everyday life with the support of active communities (Maxigas, 2012; Menichinelli, 2017). In this lively context, the format of the hackathon has grown in popularity to the point that, for example, at least one hackathon per week was organized in London in recent years (Briscoe \& Mulligan, 2014) and, according to the website hackathon.com, at least 1 hackathon per month has been organized in Copenhagen in the last 4 years.

Service design is not new to participatory formats such as workshops or jams in which different stakeholders are gathered together to collaborate on a specific challenge under the facilitation of expert designers: these formats, while sharing many characteristics with the hackathon, are usually enacted in a smaller scale and in more closed and controlled contexts (Römer, Thallmaier, Hormess, Lawrence, \& Habicht, 2011). This paper is an attempt to trace the use of the hackthon format by design researchers through the analysis of 5 hackathons that were organized between 2011 and 2017 and in which the authors of this paper had a role as participants or as organizers: The Fabriken's Hackathon and the Connectivity Lab's hackathon ran in Malmö, respectively in 2011 and 2012, the Cleaning Day "Digitalkoot" ran in 2013 in Helsinki, while Hack the outdoors and Hack4Girls were both organized in Copenhagen in 2017. The chosen hackathons are quite different from each other in many diverse dimensions, which will be carefully discussed in the comparative analysis section of the paper.

\section{The transformation of hackathons}

Hackathons were introduced in the late 90ies in Silicon Valley, as a gathering of software developers that worked together for a short and intense period of time, typically over a weekend, to prototype digital products and services or more generally to quickly solve a technical challenge. Over the years, the nature of the format has changed significantly, from being very informal, loosely organized and underground gatherings, to become well packaged events, hosted at prestigious locations with famous guests. At the same time, the expected outcome of a hackathon has moved from a working digital artefact (being a piece of code or a hacked device or an improved IT system) to less tangible outcomes, such as design concepts. Several authors introduced the definition of "civic hacking" or "philanthropic hackathons" or "social-issues hackathons" differentiating between hackathons that are technologically oriented and hackathons that are instead issue oriented (Lodato \& DiSalvo, 2016; Taylor \& Clarke, 2018; Porter, Bopp, Gerber, \& Voida, 2017). In this second type of hackathons, the focus is very often on building social ties and social relations, trying to articulate issues as a kind of material participation and not just in terms of material production. The participants are then more valued 
for their interest and knowledge about the specific challenge rather than because of their (technical or operational) skills. Many nuances are, of course, possible in between.

A possible classification of hackathons has been provided by Brisco and Mulligan (2014) that highlighted 3 different types of hackathons, i.e.:

1. Technology-focused hackathons - hackathons aimed at the application of a certain technology, either open source or company sponsored. The latter is often focused on recruiting participants; hence incentives may include prizes;

2. Business opportunity-focused hackathons (Frey \& Luks, 2016) - hackathons aimed at connecting entrepreneurs with developers, focused on testing out and pitching business ideas;

3. Social-issue focused hackathons - hackathons aimed at a social challenge and general "do good" community efforts.

Although the hackathons can be very different in nature, nowadays they all share a similar structure. They usually have a predefined duration (e.g. one or two days) and they start with the presentation of several challenges that are typically related to a common theme.

Participants - usually working in groups - collaboratively work through phases such as ideation, prototyping and, possibly, preliminary testing, following in a very condensed way design processes such as, for example, the double diamond (Stickdorn et al., 2018). At the end of the hackathon, the different groups present their solution and, in some cases, one of the groups gets an award for the promising work done. The hackathon is staged so that several actors interact with each other and with the participants: usually, there is a presenter that keeps the timing of the event, announcing the different phases/tasks of the day and entertaining the participants, several facilitators that support the work of the different groups, making sure that they have what they need in order to progress in their design process and some crucial stakeholders that provide knowledge or resources of different nature that can help the participants to articulate their solution.

Given the successful diffusion of the hackathons, a few authors studied them as an interesting case study of "contemporary sociotechnical arrangements" (Trainer, Kalyanasundaram, Chaihirunkarn, \& Herbsleb, 2016) and they also highlighted the challenges in adopting such a format. One of the criticisms towards the format is the risk of continually promoting and celebrating the figure of a tech entrepreneur hero able to undertake quick and forceful actions through overly simplistic tech solutions, instead of considering that other 'productions' might be equally important and interesting even if more intangible and less "product oriented" (Porter, Bopp, Gerber, \& Voida, 2017). Also Irani suggests that under the typical hackathon time-constraints, the tendency is to prioritize "codework over footwork", i.e. coding and instantly producing instead of having dialogues, building trust with relevant user groups or the like - slower 'footwork' demanding processes (Irani, 2015). Beside the issue of the limited impact of the hackathon's output that is often a purely tech solution to complex sociotechnical problems, D'Ignazio and colleagues pin-down some of the shortcomings of the format, such as a poor problem-selection, the inclusion-issue in terms of participation and the creation of unrealistic expectations (D'Ignazio et al., 2016). Other authors as well highlight that the challenge embedded with the format is the struggling to fully make the event inclusive, welcoming and purposeful and focused enough (Taylor \& Clarke, 2018). This is particularly relevant for issue-oriented hackathons that produce experiences of material participation rather than material production: the most important thing in this case is "how the event structures and allows for development of relations" and "how the event fosters opportunities for collaborative or collective issue articulation" (Lodato \& DiSalvo, 2016, p. 553). 


\section{Methodology}

This paper presents considerations that are derived from a case study approach (Eisenhardt, 1989; Eisenhardt \& Graebner, 2007; Yin, 2014) aimed at identifying key insights over time (Paré, 2004), within real-life contexts (Pettigrew, 1990; Yin, 2014) and using multiple sources of evidence. Through the retrospective analysis of 5 different cases, the evolution of the hackathon format will be discussed, comparing the different aims and hopes, programs, locations, outcomes and ultimately analysing the characteristics of the format from a service design perspective. The authors of the paper have been involved in the 5 different hackathons with different roles: as participants, as organizers or as facilitators. This allowed them to adopt a design research perspective where the research is engaged in the design and co-design activities studied (Zimmerman et al., 2007).

\section{The cases: 5 hackathons under investigation}

The 5 hackathons under consideration in this paper have been staged in three Nordic countries. They represent, with different degrees of sophistication, the main hackatons' typologies that Brisco and Mulligan (2014) introduced in their paper, namely the technology focused, the business focused, and the humanitarian focused. In the following paragraphs the 5 hackathons will be shortly presented.

\subsection{Hack1 / Fabriken's Hackathon (Sweden 2011)}

This hackathon took place in 2011 as a launching event for Fabriken, a makerspace situated in the city of Malmö and originated from the joint work of three local stakeholders (an NGO, a research center and an interaction design company). The hackathon was organized by these three stakeholders to involve grass-root communities interested in "making" (Porter, Bopp, Gerber, \& Voida, 2017). This focus strongly relates to Fabriken's goals and its orientation toward empowering local bottom-up initiatives. The hackathon was quite loosely structured into a 48-hour under-defined program in which the only fixed events were lunches and dinners. Rather than addressing a strictly predefined challenge, participants organized themselves in groups and tinkered with open-source hardware and software while mostly working on their own projects. The event took place in a roughly furnished warehouse with problems with the heating and the electric system. Although it was hoped that a wide number of diverse stakeholders would attend, only a handful of participants (mostly members of the existing hacker community) remained for the whole duration of the hackathon working at temperatures around $5-10^{\circ} \mathrm{C}$. Service design was not a core component of this hackathon.

\subsection{Hack2 / Connectivity Lab Hackathon (Sweden 2012)}

This was organized by a research center in Malmö to launch "Connectivity Lab", an internal unit dedicated to building closer relationships with industry and to jointly exploiting innovation and business opportunities. This hackathon was planned in great detail and was the central part of a wider two-day creators' event articulated across open talks (with invited international speakers from BBC, Arte, Georgia Tech, and various fab labs) and some workshops open to the general public (e.g., Arduino, 3D in fashion design, mobile and game design). The challenge proposed to the participants was to create innovative prototypes in the field of connected devices and social media. The hackathon was moderated to a high degree by the main organizers, and at the end of the 24-hour period allocated for the hackathon, a jury selected and presented awards to the best projects before a closing party. The hackathon took place in a 
highly-curated space and a club-like atmosphere enlivened by a DJ and kiosks providing free beer and organic coffee. The event was advertised on a large scale by also paying attention to the consistency and coherence of the communication strategy and branding qualities. Although a good number of people (350) showed up for the whole event, participants were mostly students. Very few companies or representatives from other local organizations showed up. In terms of outcomes of the hackathon, most of the participants elaborated interaction design ideas that could potentially involve services but without clearly articulating these ideas in relation to service design.

\subsection{Hack3 / Cleaning Day "Digitalkoot" (Finland 2013)}

This event was co-organised by the teachers and students of the Master level course New Media for the Digital Sector provided by the Aalto University to New Media and Design students. Its aim was to create a mobile app as well as a series of "non-technical stuff" for the event called Cleaning Day, which was created by the NGO Yhteismaa Oy. Cleaning day (see e.g. Horelli et al., 2015). The event was advertised as "digitalkoot" to "create and hack". The word "digitalkoot" is a combination of "digital" and the Finnish word "talkoot" which means "barn raising" and is used to refer to volunteer based activities where people come together to help each other, often for a common good (e.g. residents of an apartment building coming together to clean the shared spaces during one morning). Posters of the event were placed at the university's different campuses. It was opened to anyone interested, but there was also the possibility for students to receive credits for participation. A more targeted collaboration was initiated with the Department of Computer Science to support with the mobile app development during the hackathon.

This hackathon was inspired by another hackathon organised for a citizen based event in Helsinki, the Restaurant Day (RD); when anyone can sell food on the streets of Helsinki, without any special authorization required. The founders of $\mathrm{RD}$, together with a service design agency had created a successful hackathon in 2011, which resulted in the RD mobile App. This hackathon was a 2 day one, with participants from other creative companies, students, and freelancers. In the Cleaning day case however, a conscious decision was made to adapt the usual hackathon format to something different, not focused only on the production of technological artifacts like mobile apps. The aim was to encourage non technical design students to participate and therefore the possibility to produce "non technical stuff", which would be relevant to Cleaning day and the NGO.

During the Hackathon, 45 participants created "How to" guides, price tags and promotional digital videos. A mobile application was also coded to support "way finding" during Cleaning Day.

\subsection{Hack4 / Hack the outdoors (Denmark 2017)}

This hackathon took place in Aalborg in 2017 and it was part of a series of hackathons organized within the EU-funded Open4Citizens project that experimented with new forms of collaboration between citizens, public authorities, interest groups, local businesses and IT experts with the aim of (1) aggregating communities around open data, (2) developing a set of practices and infrastructures for using such data and (3) proposing a new generation of public and private services based on the use of open data. The project focused on open data as a new shared resource and aimed to generate the conditions for this resource to be used and managed as a commons (Bollier, 2014; Ostrom, 1990) and was articulated in 5 pilots in Barcelona, Copenhagen/Aalborg, Karlstad, Milan and Rotterdam. The citizens' participation in the pilots 
was mostly supported through the organization of hackathons (Concilio, Molinari, \& Morelli, 2017; Morelli, de Götzen, \& Simeone, 2018; Seravalli \& Simeone, 2016), which would bring together a local community with shared interests in specific problematic areas, thus creating an ecosystem to generate or consolidate the demand for open data or to organize crowdsourced gathering of new open data.

The Hack the Outodoors hackathon has been organized in collaboration with local stakeholders such as Open Data Nordjylland and InfinIT - Innovationsnetværk for IT and it has been carefully prepared through a series of pre-hack events in which around 15 municipalities of Nordjylland were invited to share their interest and perspective in smart tourism. Post hackathons events followed as well with the aim of supporting the development of the most promising ideas also after the event itself. The hackathon took place at Aalborg University during a weekend, it has been widely advertised and got the attention of around a 100 of participants, mostly students from the university, but members from nine local administrations and public organization also participated, by proposing design challenges and supporting the hackathon groups. A professional facilitator was engaged to conduct the event, while mostly researchers from the open4citizens project were facilitating the groups' work. At the end of the hackathon the participants produced mostly early concept ideas and early digital mock-ups about smart solutions related to tourism and they pitched them in front of a selected jury. The 3 best projects were selected and got different prizes. Only few groups used in an actual script the datasets provided for the hackathon and the generated concept where mostly early service ideas.

\subsection{Hack5 / Hack4Girls (Denmark 2017)}

This hackathon took place in Copenhagen and was aimed at developing new solutions for refugee girls and women in Sub Saharan Africa. The event was hosted and sponsored by Atea Future Growth, Maternity Foundation, Microsoft, Save the Children, the Ministry of Foreign Affairs and the United Nations Population Fund. Being part of a good cause, it attracted many other parties that joined and supported the hackathon. Beside the different organisations that volunteered to host the event, 22 experienced mentors joined the hackathon. The organizers advertised the event mainly through social media and got the attention of a large number of people. Before the hackathon, an information package and the design brief were sent to the participants. During the registration t-shirts with three different colors were distributed in order to easily identify the background of the participants in terms of design, technology, business or other fields. The participants were asked to wear t-shirts during all the weekend. The teams were formed and named according to the interests to the different presented challenges and at the end of 36-hour hackathon they pitched their concept with a short presentation. The three best ideas selected by the internal jury were presented a second time at the grand finale event, two days after. Her Royal Highness the Crown Princess of Denmark and Minister for Development Cooperation, attended the finale event. The three finalists presented their proposals to a panel of judges, including CEO of Microsoft Denmark, international entrepreneur and chair of UN Live Online, Secretary General of Save the Children Denmark and founder of Whywoman.org. After the pitch, a girls' choir of newcomers in Denmark performed a short concert. Following the show, the winning pitch was announced, and the team received a concept development and incubation support price of DKK 25.000 from different organisations. The event ended with cocktails. As a side note, due to the special guests of the grand finale, a second registration was needed to attend it and only the three best teams wore their \#Hack4girls t-shirts. The rest of the audience dressed according to the presence of the royal family member and the fanciness of the event. 


\section{Comparative analysis}

From the overview of the 5 selected hackathons it is clear that they are quite different in many ways: while Hack1 focused on engaging local communities in a loosely organized event, Hack3 brought forward non-technological outcomes and Hack5 was staged within a very formal and strict protocol, according to which participants should also wear an appropriate outfit for the fancy final event also attended by Her Royal Highness the Crown Princess of Denmark. While Hack2 had a clear entrepreneurial/business goal, Hack4 was mainly experimenting with research tools and methods with the aim of exploring citizens engagement in using open data to develop meaningful public and private services. Different dimensions could be used to describe the hackathons; in this paper, the comparative analysis has been carried out focusing on 6 main parameters: Aims, Preparation and Communication, Program, Location and Stakeholders involved, Outcomes, Relation with Service Design. While the first 5 parameters are considered relevant to capture the nature of the hackathons, the last one is added because of the specific focus adopted by this paper on service design. The main findings have been summarized in Table 1 .

Table 1. Summary of the main characteristics of the 4 hackathons according to the six chosen parameters.

\begin{tabular}{|c|c|c|c|c|c|}
\hline & Hack1 (2011) & Hack2 (2012) & Hack3 (2013) & Hack4 (2017) & Hack5 (2017) \\
\hline $\operatorname{Aims}$ & $\begin{array}{l}\text { Participants organized } \\
\text { themselves in groups } \\
\text { and tinkered with } \\
\text { open-source hardware } \\
\text { and software while } \\
\text { mostly working on } \\
\text { their own projects. }\end{array}$ & $\begin{array}{l}\text { Create innovative } \\
\text { prototyping in the } \\
\text { field of connected } \\
\text { devices and social } \\
\text { media }\end{array}$ & $\begin{array}{l}\text { Create a mobile and } \\
\text { other "non technical } \\
\text { stuff" for an NGO }\end{array}$ & $\begin{array}{l}\text { Developing new } \\
\text { smart tourism } \\
\text { services through } \\
\text { the use of open } \\
\text { data }\end{array}$ & $\begin{array}{l}\text { Inspirational event } \\
\text { for good cause to } \\
\text { develop new } \\
\text { solutions for } \\
\text { refugee girls and } \\
\text { women in Sub } \\
\text { Saharan Africa }\end{array}$ \\
\hline $\begin{array}{l}\text { Preparation } \\
\text { \& } \\
\text { communicat } \\
\text { ion }\end{array}$ & $\begin{array}{l}\text { Not many resources } \\
\text { invested }\end{array}$ & $\begin{array}{l}\text { Well planned and } \\
\text { communicated } \\
\text { through a coherent } \\
\text { and consistent } \\
\text { strategy }\end{array}$ & $\mid \begin{array}{l}\text { Not many resources } \\
\text { invested }\end{array}$ & $\begin{array}{l}\text { A lot of resources } \\
\text { invested in the } \\
\text { mobilization of the } \\
\text { ecosystem and } \\
\text { communication of } \\
\text { the event }\end{array}$ & $\begin{array}{l}\text { Promotion through } \\
\text { social media and } \\
\text { well prepared } \\
\text { information } \\
\text { package for } \\
\text { participants }\end{array}$ \\
\hline Programs & $\begin{array}{l}\text { Open and under- } \\
\text { defined format }\end{array}$ & Defined in advance & Defined in advance & $\begin{array}{l}\text { Very structured } \\
\text { and detailed even } \\
\text { including pre- } \\
\text { hackathon and } \\
\text { post-hackathon } \\
\text { phases }\end{array}$ & $\begin{array}{l}\text { Open and under- } \\
\text { defined format }\end{array}$ \\
\hline $\begin{array}{l}\text { Locations, } \\
\text { stakeholder } \\
s \quad \text { involved } \\
\text { and } \\
\text { participants }\end{array}$ & $\begin{array}{l}\text { Location: a cold and } \\
\text { roughly furnished } \\
\text { warehouse. } \\
\text { Stakeholders: local } \\
\text { hacker community, } \\
\text { managers of the } \\
\text { hosting makerspace } \\
\text { Participants: mostly } \\
\text { local hacker } \\
\text { community }\end{array}$ & $\begin{array}{l}\text { Location: a quite } \\
\text { curated setting for a } \\
\text { party-like staging. } \\
\text { Stakeholders: } \\
\text { university } \\
\text { researchers, } \\
\text { students, local } \\
\text { business and } \\
\text { innovation } \\
\text { community } \\
\text { Participants: mostly } \\
\text { students (industry } \\
\text { was missing) }\end{array}$ & $\begin{array}{l}\text { Location: Aalto } \\
\text { University's Media } \\
\text { Factory } \\
\text { Stakeholders: NGO, } \\
\text { teachers form two } \\
\text { departments } \\
\text { Participants: above } \\
\text { stakeholders and } \\
\text { Aalto university } \\
\text { students }\end{array}$ & $\begin{array}{l}\text { Location: Aalborg } \\
\text { University in } \\
\text { Aalborg. The } \\
\text { rooms } \\
\text { organized were } \\
\text { prepared and } \\
\text { advance with all } \\
\text { the material } \\
\text { needed by the } \\
\text { participants } \\
\text { Stakeholders: } \\
\text { Several } \\
\text { municipalities and }\end{array}$ & $\begin{array}{l}\text { Location: in an } \\
\text { office of a design } \\
\text { company. } \\
\text { Final event took } \\
\text { place in a larger } \\
\text { venue close to the } \\
\text { main location } \\
\text { Stakeholders: } \\
\text { Several companies } \\
\text { supporting the } \\
\text { event } \\
\text { Participants: } \\
\text { mixed young }\end{array}$ \\
\hline
\end{tabular}




\begin{tabular}{|c|c|c|c|c|c|}
\hline & & & & $\begin{array}{l}\text { Innovation } \\
\text { companies } \\
\text { Participants: } \\
\text { mostly students }\end{array}$ & $\begin{array}{l}\text { professionals and } \\
\text { students }\end{array}$ \\
\hline Outcomes & Mostly hacks & $\begin{array}{l}\text { Ideas for interaction } \\
\text { design projects } \\
\text { presented in a final } \\
\text { competition with } \\
\text { jury and prizes }\end{array}$ & $\begin{array}{l}\text { Rough mobile app, } \\
\text { Illustrated "How to" } \\
\text { instructions, } \\
\text { promotional video, } \\
\text { collection of studies }\end{array}$ & $\begin{array}{l}\text { Ideas for possible } \\
\text { services presented } \\
\text { in the final } \\
\text { competition with } \\
\text { jury and prizes - } \\
\text { also for the worst } \\
\text { idea. }\end{array}$ & $\begin{array}{l}\text { Conceptual ideas } \\
\text { (mainly } \\
\text { technological - } \\
\text { apps) projects } \\
\text { presented in a final } \\
\text { competition with } \\
\text { jury and prizes }\end{array}$ \\
\hline $\begin{array}{l}\text { Relation } \\
\text { with service } \\
\text { design }\end{array}$ & $\begin{array}{l}\text { Definitely not central } \\
\text { for this hackathon }\end{array}$ & $\begin{array}{l}\text { Some groups } \\
\text { worked on ideas that } \\
\text { involved services, } \\
\text { but service design } \\
\text { remained in the } \\
\text { background }\end{array}$ & $\begin{array}{l}\text { Indirect as the } \\
\text { outcomes were to be } \\
\text { part of the services } \\
\text { co-produced by the } \\
\text { NGO together with } \\
\text { interested citizens of } \\
\text { Helsinki }\end{array}$ & $\begin{array}{l}\text { The ideas } \\
\text { generated were } \\
\text { services for the } \\
\text { tourism industry. } \\
\text { The participants } \\
\text { went through a } \\
\text { service design } \\
\text { process using the } \\
\text { toolbox of the } \\
\text { discipline. }\end{array}$ & $\begin{array}{l}\text { The ideas were } \\
\text { related to service } \\
\text { concepts, mainly } \\
\text { apps. }\end{array}$ \\
\hline
\end{tabular}

The table shows how Hack1 resembled more to the original hackathon format, while Hack2, 3,4 and 5 were more codified and formalised in terms of the processes that had to take place (the competition format including presentations to a jury and a prize), and only Hack 2, 4 and 5 in terms of the communication and preparation strategy (with a lot of investment in setting the scene), in terms of goals (a marketing one for Hack2, a solution development for Hack4 and Hack5 with different levels of specification) and in terms of location and stakeholders involved (nice and well prepared locations, set up in collaboration with - or with the support of - many other stakeholders involved in the event). It is also interesting to notice that the more a hackathon had the design of services as a possible goal, the more stakeholders had to be involved in the preparation of the event (Hack4 and Hack5), while in Hack1, the set of involved stakeholders was much more limited.

\section{Discussion}

The five hackathons analysed in this paper took place over the span of 6 years and it is interesting to notice how their placement over time has a role in the characterization of the different events. We can argue that the first hackathon was the only one representing the original idea of the format: a loosely organized event for highly motivated programmers that very often were already belonging to a hacker community. In this kind of event, service design was definitely not in the foreground, both in terms of the organization and facilitation of the event and in terms of the desired outcomes, which were mostly of technical nature. Already existing local hacking communities were the main driver of such events and the participants of the hackathons would only interact with external stakeholders in a limited fashion and would feel that they already possess the knowledge and the tools to achieve the goal set by the hackathon. As time passed by, it is possible to notice how the hackathon format has evolved from being an event for coders (Hack1), to becoming a more business-driven event (Hack2 and partially Hack4), or an event supporting a specific not-for-profit cause (Hack3) and eventually adopting a format that can challenge the participants with wider and timely social issues (Hack 5). With 
the later versions (Hacks3,4,5), we might start talking of hybrids of hackathons and design sprints or workshops, where time-condensed design iteration cycles based on divergent and convergent thinking (e.g. the Double Diamond) are brought into what was originally a less structured hacking event. We are aware that our own involvement in these hackathons, especially as organisers (e.g. in Hack3) has contribute to the move away from the original hackathon format and goals, but our experience in these hackathons through the years also show that back in 2011 it was not yet possible to imagine new formats or goals, because hackathons were so new.

It is quite clear that the evolution of the format implied the involvement of different stakeholders, with different backgrounds, motivations and goals, broadening the scope of the event itself. In such a context, the event has to be carefully planned, facilitators have to be involved and the professional domain of service design comes in handy as a more visible field of practice and research able to engage both with citizens and public authorities. The expertise of service design has been deemed as necessary or helpful when deployed in relation to complex public and organisational challenges (Bason, 2010, 2017; Kimbell, 2015, 2019). As such, bringing service design into the hackathon process puts the focus on the practical generation and exploration of new ideas that allow the different stakeholders to collaborate across the silos of their expertise and interests empowering at the same time the perspectives of beneficiaries and citizens. It is clear that the outcome of such service-design-driven hackathons cannot be as concrete and product-oriented as in the original format and, at the same time, to create value in complex service ecosystems, the events need to be more carefully structured. The service design perspective and the participation of experts from this area also bring about a solid structure for the design process, which starts from the identification and mobilisation of the ecosystem in the pre-hackathon phases and continues during the actual hackathon, with the proposition of collaborative tools.

It can be questioned what is specific to such service-design-driven hackathons versus other collaborative formats like design workshops? On the one hand, it can be said that the term hackathon has become a buzzword in the public and private innovation landscape, able to attract stakeholders under the promise of delivering quick solutions in a short amount of time: in this context, naming an event as hackathon has become more a matter of marketing than a matter of content. On the other, with digitalization becoming such a crucial aspect of services, the hackathon format might (once again) better interpret the needs of the organizers without betraying its original identity: as an example, Hack 4, with a clear focus on open data and citizen empowerment, could not be a workshop, because digital hacking of available datasets was actually needed to provide a final design for a new service.

From a service design perspective however, the biggest limitation of the format is the impact that the event itself produces in the ecosystem that has been mobilized. Concept ideas very rarely are developed after the event and it is quite difficult to measure how much the event per se produced "experiences of material participation" that lasted after the event or that will be used as a first step towards a new network of relations among stakeholders. Hack2 and Hack4 are clear examples of this issue up to a point where it could be questioned if these kinds of events are becoming more and more marketing events and celebrations where the proposed challenges are just instrumental to raise awareness about specific issues or to just tell the public at large that a new stakeholder (lab, organization, company) is active in the city.

\section{Conclusions}

This paper presented a non-exhaustive review of the hackathon format, based on five different hackathons organized between 2011 and 2017, with the aim of outlining the different 
interpretation of the format from a service design perspective. We are aware of the limitations of the study, which is limited to five cases in the Nordic countries, but we believe they provide an overview over time of the evolution of hackathons in this part of the world. Furthermore, our own engagement in these cases is an example of the interest of the design and design research community in trying and testing, and eventually adapting, the hackathon activity as a collaborative design format.

With respect to the early, pioneering times, hackathons are changing and, one may argue, loosing part of their spontaneity and productivity, although only a small part of the results of the early hackathons could really be used or developed beyond their initial experimental phase. The evolution documented in the five cases in this paper however, is going towards organisations and models that could benefit from service design and, in turn, could contribute to the methodological construction of this discipline. This may in turn allows for hackathons to be more heterogeneous spaces of co-creations, bringing together more techy developers and other designers, including service designers, to work together in a co-located venue.

From this perspective, hackathons are becoming part of a palette of tools used to engage with different stakeholders and to explore specific challenges. Such tools are design and innovation sprints and workshops, which tend to involve a relatively small number of participants and that are used internally in an organization to speed up the design process or to involve different departments in an ideation session, to align across departments on a specific need of the company/organization or to spread a new working culture. Hackathons are, instead, very often organized at a bigger scale and within a public dimension, involving the collaboration of many different stakeholders. In the last decades, the format of the hackathons has dramatically changed and their preparation has become quite heavy in terms of logistic and ecosystem mobilization, becoming top-driven events that do not have any longer much in common with the original idea of self-organized and bottom up events. This change is highlighting the tension between the original nature of the hackathon as an agile, though sometimes too playful tool for nerds and a new function, that, especially in the pre-hackathon phases, aggregates an ecosystem. Although participation is still one of the crucial aspects, very often the implicit goal of the event is to build communities that do not exist yet (as the case of Hack4 and Hack5) but that could make a change in the existing ecosystem to solve challenges that cannot be easily approached by single stakeholders/communities. We can even imagine that, in times of COVID19 and forced online collaboration, hackathons will evolve as a completely digital format able to strengthen communities in the creation of new common and digital spaces to approach completely new kind of challenges.

The orchestration of the stakeholders will remain then the pivotal aspect for a successful hackathon and we can argue that service design, with its focus on the socio technical systems in which it operates, has already a set of tools and processes to work toward this orchestration. In other words, rather than trying to solve this paradox, this paper is suggesting that Service Design will possibly be a good disciplinary ground to explore the tension between the original hackathon format and the most recent developments of this genre of collaborative design.

\section{References}

Bason, C. (2010). Leading public sector innovation: Co-creating for a better society. Bristol, UK ; Portland, OR: Policy Press.

Bason, C. (2017). Leading public design: Discovering human-centred governance. Bristol Chicago, IL: Policy Press. 
Bollier, D. (2014). Think Like a Commoner: A Short Introduction to the Life of the Commons. Gabriola, British Columbia: New Society Publishers.

Briscoe, G., \& Mulligan, C. (2014). Digital Innovation: The Hackathon Phenomenon. Retrieved from Queen Mary University of London/Faculty of Humanities, Social Sciences \& Law website: http://qmro.qmul.ac.uk/xmlui/handle/123456789/11418

Concilio, G., Molinari, F., \& Morelli, N. (2017, May). Empowering Citizens with Open Data by Urban Hackathons. 125-134. https://doi.org/10.1109/CeDEM.2017.28

Concilio, G., De Götzen, A., Molinari, F., Morelli, N., Mulder, I., Simeone, L., Van Dam, K. (2018). Innovation and Design. In G. Concilio \& I. Tosoni (Eds.), Innovation Capacity and the City (pp. 56-72). Milano: Springer.

D'Ignazio, C., Hope, A., Metral, A., Brugh, W., Raymond, D., Michelson, B., Zuckerman, E. (2016). Towards a feminist hackathon: The "make the breast pump not suck." Journal of Peer Production, Feminism and (un)hacking(8). Retrieved from http://peerproduction.net/issues/issue-8-feminism-and-unhacking-2/peer-reviewedpapers/towards-a-feminist-hackathon-the-make-the-breast-pump-not-suck/

Eisenhardt, K. M. (1989). Building Theories from Case Study Research. The Academy of Management Review, 14(4), 532. https://doi.org/10.2307/258557

Eisenhardt, K. M., \& Graebner, M. E. (2007). Theory Building From Cases: Opportunities And Challenges. Academy of Management Journal, 50(1), 25-32. https://doi.org/10.5465/amj.2007.24160888

Frey, F. J., \& Luks, M. (2016). The innovation-driven hackathon: One means for accelerating innovation. Proceedings of the 21st European Conference on Pattern Languages of Programs - EuroPlop '16, 1-11. https://doi.org/10.1145/3011784.3011794

Horelli, L., Saad-Sulonen, J., Wallin, S. \& Botero, A. (2015) When Self-Organization Intersects with Urban Planning: Two Cases from Helsinki. Journal of Planning Practice \& Research, 30:3, 286-302, https://doi.org/10.1080/02697459.2015.1052941

Irani, L. (2015). Hackathons and the Making of Entrepreneurial Citizenship. Science, Technology, \& Human Values, 40(5), 799-824. https://doi.org/10.1177/0162243915578486

Kimbell, L. (2015). Applying Design Approaches to Policy Making: Discovering Policy Lab. Brighton, Uk: University of Brighton.

Kimbell, L. (2019). What If There Were More Policy Futures Studios? Journal of Futures Studies, 23(4), 129-136. https://doi.org/10.6531/JFS.201906_23(4).0014

Linnell, N., Figueira, S., Chintala, N., Falzarano, L., \& Ciancio, V. (2014). Hack for the homeless: A humanitarian technology hackathon. Global Humanitarian Technology Conference (GHTC), 577-584. https://doi.org/10.1109/GHTC.2014.6970341

Lodato, T. J., \& DiSalvo, C. (2016). Issue-oriented hackathons as material participation. New Media \& Society, 18(4), 539-557. https://doi.org/10.1177/1461444816629467

Manzini, E., \& Staszowski, E. (2013). Public and Collaborative: Exploring the Intersection of Design, Social Innovation and Public Policy (p. 181). DESIS.

Maxigas, P. (2012). Hacklabs and hackerspaces - tracing two genealogies. Journal of Peer Production, (2).

Menichinelli, M. (2017). Notes for future research on the impact of the Fab Lab network. Fabricating Society - Research Book, 34-44.

Morelli, N., Aguilar, M., Concilio, G., Götzen, A. D., Mulder, I., Pedersen, J., \& Torntoft, L. K. (2017). Framing Design to support Social Innovation: The Open4Citizens Project. The Design Journal, 20(sup1), S3171-S3184. https://doi.org/10.1080/14606925.2017.1352823 
Morelli, N., de Götzen, A., \& Simeone, L. (2018). A system of innovation to activate practices on open data: The Open4Citizens project. Proceedings of 3rd International Conference on Smart Learning Ecosystem and Regional Development - The Interplay of Data, Technology, Place and People. Aalborg, Denmark.

Ostrom, E. (1990). Governing the commons: The evolution of institutions for collective action. Cambridge: Cambridge University Press.

Paré, G. (2004). Investigating Information Systems with Positivist Case Research. Communications of the Association for Information Systems, 13(1). Retrieved from http://aisel.aisnet.org/cais/vol13/iss1/18

Pettigrew, A. M. (1990). Longitudinal Field Research on Change: Theory and Practice. Organization Science, 1(3), 267-292. Retrieved from JSTOR.

Porter, E., Bopp, C., Gerber, E., \& Voida, A. (2017). Reappropriating Hackathons: The Production Work of the CHI4Good Day of Service. Proceedings of the $2017 \mathrm{CHI}$ Conference on Human Factors in Computing Systems - CHI '17, 810-814. https://doi.org/10.1145/3025453.3025637

Römer, M., Thallmaier, S. R., Hormess, M., Lawrence, A., \& Habicht, H. (2011). Jams as emerging practice of innovation communities: The case of the global service jam 2011. Gi-Jahrestagung. Retrieved from https://www.semanticscholar.org/paper/Jams-asemerging-practice-of-innovation-the-case-of-R\%C3\%B6merThallmaier/038e5b968fe4a55cc2193db3d2d0c8256372f55b

Seravalli, A., \& Simeone, L. (2016). Performing Hackathons as a way of positioning boundary organizations. Journal of Organizational Change Management, 29(3), 326-343.

Stickdorn et al. (2018). This is Service Design Doing. Applying Service Design Thinking to the Real World. Canada: O'Reily Media.

Tanenbaum, K., Glen Tanenbaum, J., Williams, A. M., Ratto, M., Resch, G., \& Gamba Bari, A. (2014). Critical making hackathon: Situated hacking, surveillance and big data proposal. CHI '14 Extended Abstracts on Human Factors in Computing Systems, 1720. Toronto, Ontario, Canada: ACM.

Taylor, N., \& Clarke, L. (2018). Everybody's Hacking: Participation and the Mainstreaming of Hackathons. Proceedings of the 2018 CHI Conference on Human Factors in Computing Systems - CHI '18, 1-12. https://doi.org/10.1145/3173574.3173746

Trainer, E. H., Kalyanasundaram, A., Chaihirunkarn, C., \& Herbsleb, J. D. (2016). How to Hackathon: Socio-technical Tradeoffs in Brief, Intensive Collocation. Proceedings of the 19th ACM Conference on Computer-Supported Cooperative Work \& Social Computing - CSCW '16, 1116-1128. https://doi.org/10.1145/2818048.2819946

Yin, R. (2014). Case Study Research Design and Methods. The Canadian Journal of Program Evaluation. https://doi.org/10.3138/cjpe.30.1.108 